\title{
Behavior, Histopathology and Physiological Responses of Rat Fed Diets Containing Growth Hormone Transgenic Fish Meal
}

\author{
Alimuddin Alimuddin ${ }^{1 *}$, Sri Murtini ${ }^{2}$, Nurly Faridah ${ }^{3}$, Sri Nuryati \\ ${ }^{1}$ Aquaculture Department, Bogor Agricultural University, Bogor, Indonesia \\ ${ }^{2}$ Medical Microbiology Division, Department of Animal Diseases and Veterinary Public Health, IPB, Bogor, Indonesia \\ ${ }^{3}$ Main Center of Freshwater Aquaculture, Sukabumi, Indonesia
}

ARTICLE INFO

Article history:

Received April 26, 2017

Received in revised form November 13, 2017

Accepted November 20, 2018

\section{KEYWORDS:}

Behavior,

physiology,

toxicity,

transgenic common carp,

Wistar rat

\begin{abstract}
The animal model response against genetically modified product may provide food safety information. This study was performed to observe behavior, histopathology and physiological responses of Wistar rat fed on the diet containing growth hormone $(\mathrm{GH})$ transgenic common carp (Cyprinus carpio) meal $(\mathrm{Ccm})$. Thirty rats of three-month-old (BW: 115.67-139.50g) were divided into five treatments (six rats per treatment). The treatments were rats fed on the commercial diet without $\mathrm{Ccm}$ (control), a re-pelleted diet containing 15\% (NT-15) and $45 \%$ non-transgenic $\mathrm{Ccm}$ (NT-45), a re-pelleted diet containing $15 \%$ (TG-15) and $45 \%$ GH transgenic Ccm (TG-45). Rats were kept for three weeks, fed twice a day according to treatment by $30 \mathrm{~g} / \mathrm{day} / \mathrm{rat}$ and water was provided ad-libitum. Rat behavior was observed every day during feeding. Serum glutamic oxaloacetic transaminase (SGOT), serum glutamic pyvuric transaminase (SGPT), urea, and creatinine were measured at initial and the end of the experiment. Histology observation was made for liver, kidney, and brain tissues. Our results showed that behavior, histopathology, SGOT, SGPT, urea and creatinine levels of rat fed with control, NT- and TG-Ccm diets were similar. All rats survived until the end of the experiment. Thus, within the dose level of this study, GH transgenic $\mathrm{Ccm}$ showed no toxicity or effect on behavior and physiology of Wistar rats.
\end{abstract}

\section{Introduction}

Common carp (Cyprinus carpio L.) is one of the important commodities in Indonesia freshwater aquaculture. In order to arouse activity and support for increasing common carp aquaculture production, the authors have developed koi herpesvirus (KHV) resistant common carp strain (Alimuddin et al. 2011), which has been released by the Ministry of Marine and Fishery on 2015. In addition, as a part of common carp genetic quality improvement program in Indonesia, transgenic common carp fish whose second generation expressed Nile tilapia growth hormone $(\mathrm{GH})$ gene has been produced (Alimuddin et al. 2012). These fishes also exhibit molecular marker associated with KHV infection resistance. The result of limited field test showed that growth of GH transgenic common carp has 27.5-338.8\% higher compared to non-transgenic fish (Alimuddin et al. 2013). By using the same gene

\footnotetext{
* Corresponding Author

E-mail Address: alimuddin@apps.ipb.ac.id
}

construction, the growth of transgenic Nile tilapia fish reached 2-7 times higher than its non-transgenic counterparts (Kobayashi et al. 2007).

According to Republic of Indonesia Government Policy No. 21 the Year 2005 on the safety of the genetically modified product (GMP) which includes Indonesian GMP fish, there is a need for evaluation of environmental and food safety before products may be recommended to be maintained by the farmers. Some parameters concerning environmental and food safety have been evaluated in the last research. The parameters were reproductive performance, fatty acid and amino acid contents (Alimuddin et al. 2014), proximate composition, feed conversion efficiency and ammonia excretion of $\mathrm{GH}$ transgenic common carp (Kurdiantho et al. 2016). Meanwhile, recently there has been a report that GH transgenic salmon fish has been officially deemed safe for consumption and environment in the USA (FDA 2016).

The complexity of social behaviors and the flexibility required for normal social interactions in animal make social behavior is particularly susceptible 
to disruption. Types of disruption that affect behavior include changes in the type of feed. Rats are arguably the most successful, and surely the most widely distributed, nonhuman mammals on Earth. Research reports on diverse feed changes in mice do not significantly affect behavioral change because rats enjoy results from the extraordinary range of foods that they are able to exploit (Galef 2005). However, the behavior of mouse-related feed that affects the behavior occurs when the feed given affects health conditions such as causing death. In addition, mice learn about the type of feed so that mice will only eat the feed provided if the feed does not cause death (Armario 2006).

As used in transgenic salmon (Devlin et al. 1994), common carp transgenic used in this study is also carrying fish derived $\mathrm{GH}$ gene. In our previous research, the use of fresh meat of GH transgenic common carp in feed did not influence survivability, feeding response and growth of African catfish and giant freshwater prawn which acted as the carnivorous fish model (Alimuddin et al. 2013). To complete information regarding the food safety of $\mathrm{GH}$ transgenic common carp, this research was made to test the response of animal model against feed mixed with those fish meal. In this study rat was used as an animal model to evaluate whether feeding the diets containing transgenic fish meal causes stress and behavioral changes characterized by decreased body weight, other social behaviors (such as digging, interaction between rats), and eating behavior. The study aimed to explore whether the $\mathrm{GH}$ transgenic common carp F2 generation is associated with adverse effects on mammals after oral intake, with putative relevance to humans, by observing the behavior, histopathological tissues, liver and kidney function and growth of Wistar rat.

\section{Materials and Methods}

\subsection{Feed Preparation}

Two kilograms of second generation transgenic common carp carrying growth hormone gene (Alimuddin et al. 2013) and non-transgenic common carp were separately made into fish meal. The making of fish meal was done in Fish Nutrition Laboratory, Aquaculture Department, Bogor Agricultural University (IPB). Fishes were cut into several small parts, including head, meat and innards then dried in a $60^{\circ} \mathrm{C}$ oven for 48 hours. The fishes were then ground into soft meal. Commercial diet for rats was crushed, mixed with fish meal previously made according to treatment (Table 1 ), and then re-pelleted into $2-\mathrm{mm}$ sized pellet. Diets were dried at $60^{\circ} \mathrm{C}$ for 24 hours, then stored in the refrigerator until used.
Table 1 . Amount of fish meal mixed with rat commercial diet

\begin{tabular}{|c|c|}
\hline Treatments & Description \\
\hline Control & Feeding with commercial diet \\
\hline NT-15 & $\begin{array}{l}\text { Feeding with repelleted commercial } \\
\text { diet containing } 150 \mathrm{~g} / \mathrm{kg} \text { diet of non- } \\
\text { transgenic (NT) common carp meal } \\
(\mathrm{Ccm})\end{array}$ \\
\hline NT-45 & $\begin{array}{l}\text { Feeding with repelleted commercial } \\
\text { diet containing } 450 \mathrm{~g} / \mathrm{kg} \text { diet of non- } \\
\text { transgenic (NT) common carp meal } \\
(\mathrm{Ccm})\end{array}$ \\
\hline TG-15 & $\begin{array}{l}\text { Feeding with repelleted commercial diet } \\
\text { containing } 150 \mathrm{~g} / \mathrm{kg} \text { diet of growh } \\
\text { hormone transgenic (TG) common } \\
\text { carp meal }(\mathrm{Ccm})\end{array}$ \\
\hline TG-45 & $\begin{array}{l}\text { Feeding with repelleted commercial diet } \\
\text { containing } 450 \mathrm{~g} / \mathrm{kg} \text { diet of growth } \\
\text { hormone transgenic (TG) common } \\
\text { carp meal (Ccm) }\end{array}$ \\
\hline
\end{tabular}

\subsection{Rats Housing Condition and Observation}

Rats used in this research were male Wistar rat aged 3 months (body weight: 115.67-139.50g), obtained from National Agency of Drug and Food Control, Jakarta, Indonesia. Five treatments and three replications were provided in this study (Table 1 ) and each treatment consisted of six rats (2 rats per cage). Rats were housed in Laboratory Animal Housing Unit, Veterinary Medicine Faculty, IPB according to laboratory animal care standard (VAPHS 2016). Rats were acclimatized at $21 \pm 1^{\circ} \mathrm{C}$ in an individual cage $\left(10 \times 25 \times 40 \mathrm{~cm}^{3}\right)$ for a week and given commercial diet as much as $30 \mathrm{~g} / \mathrm{day} / \mathrm{rat}$. Afterwards, rats were reared for 3 weeks under 12L:12D, fed on the tested diet as much as $30 \mathrm{~g} / \mathrm{day} / \mathrm{rat}$, twice a day (morning and afternoon) and water was provided ad-libitum.

Observation of rat behavior regarding to feed treatment is sufficient for three weeks. The behavioral changes are observed differently when dietary behavior related to induction effect, such as effect on the central nervous system is only observed in 120 minutes (Stratford and Kelle 1997) and related to health in other studies is conducted for one week (Geiger et al. 2009).

Animal behavior was observed every day at each time of feeding for 30 minutes and physical conditions such as wounds. The behavior observed were cannibalism, social behavior (including playing, burrowing, eating, interaction with other mice, sleeping, grooming), appetite, and water intake.

Body weight was measured before treatment diet was given then continued for every week during treatment. The rat was weighted before feeding was performed in the morning. Individual weight was measured by using a digital scale with $0.01 \mathrm{~g}$ accuracy. 
Histological analysis was carried out to evaluate changes happening at the cellular level of the observed organ. Regarding the rules of welfare minimum number of rats sacrificed, at the end of treatment, liver, kidney, and brain were taken from 3 rats which represents each cage. The three organs were made into histological slides with hematoxylin-eosin staining method (Kiernan 1990).

Blood was taken from three rats before feeding treatment and from another three rats at the end of the experiment. Liver function evaluation was analyzed by measuring SGOT and SGPT concentration in the serum. Kidney function evaluation was analyzed by measuring ureum and creatinine levels. SGOT, SGPT, urea, and creatinine levels were estimated by using Diasys reagents via spectrophotometry method in Clinical Pathology Laboratory, Veterinary Medicine Faculty, IPB.

\subsection{Data Analysis}

Behavior and histopathological image were analyzed descriptively, while body weight, SGOT, SGPT, urea, and creatinine concentration were quantitatively analyzed using one-way ANOVA and Duncan test at 95\% accuracy level.

\section{Results}

\subsection{Behavior and Histopathology}

Within the three weeks observation, no behavioral differences were found between rats fed on TG-
Ccm, NT-Ccm, and commercial diet without CCm supplementation (control). All test subject did not show cannibalism behavior, interacted with other rats in the different cage, play and burrowing behaviors, sleeplessness and non-excessive urination was evidenced by non-wet conditions as in the control. Similar to behavioral response, histological observation over kidney, liver, and brain did not show any pathological changes such as macrophage infiltration, cell hyperplasia, hyperemia, or necrosis in both control and $\mathrm{Ccm}$-treated rats (Figure 1 ).

\subsection{Body Weight Gain}

According to rat weight of each treatment, it found that rats fed on $\mathrm{Ccm}$ supplemented diet had higher body weight $(\mathrm{p}<0.05)$ compared to control which was not given $\mathrm{Ccm}$ (Table 2). Body weight of NT$\mathrm{Ccm}$ and TG-Ccm treated rats started to differ with control during week 1 which continued until the end of the experiment. However, there was no significant difference in body weight between rat given TG-Ccm and NT-Ccm.

\subsection{Liver and Kidney Function}

Liver function was observed by measuring SGOT and SGPT enzymes before (initial condition) and after diet treatment was given for 3 weeks. As presented in Table 3, average SGOT and SGPT values before treatment were $178.3 \pm 12.85 \mathrm{IU} / \mathrm{l}$ and $144.7 \pm 11.54 \mathrm{IU} / \mathrm{l}$, respectively. SGOT and SGPT concentration after diet treatment have decreasing trend, though the values

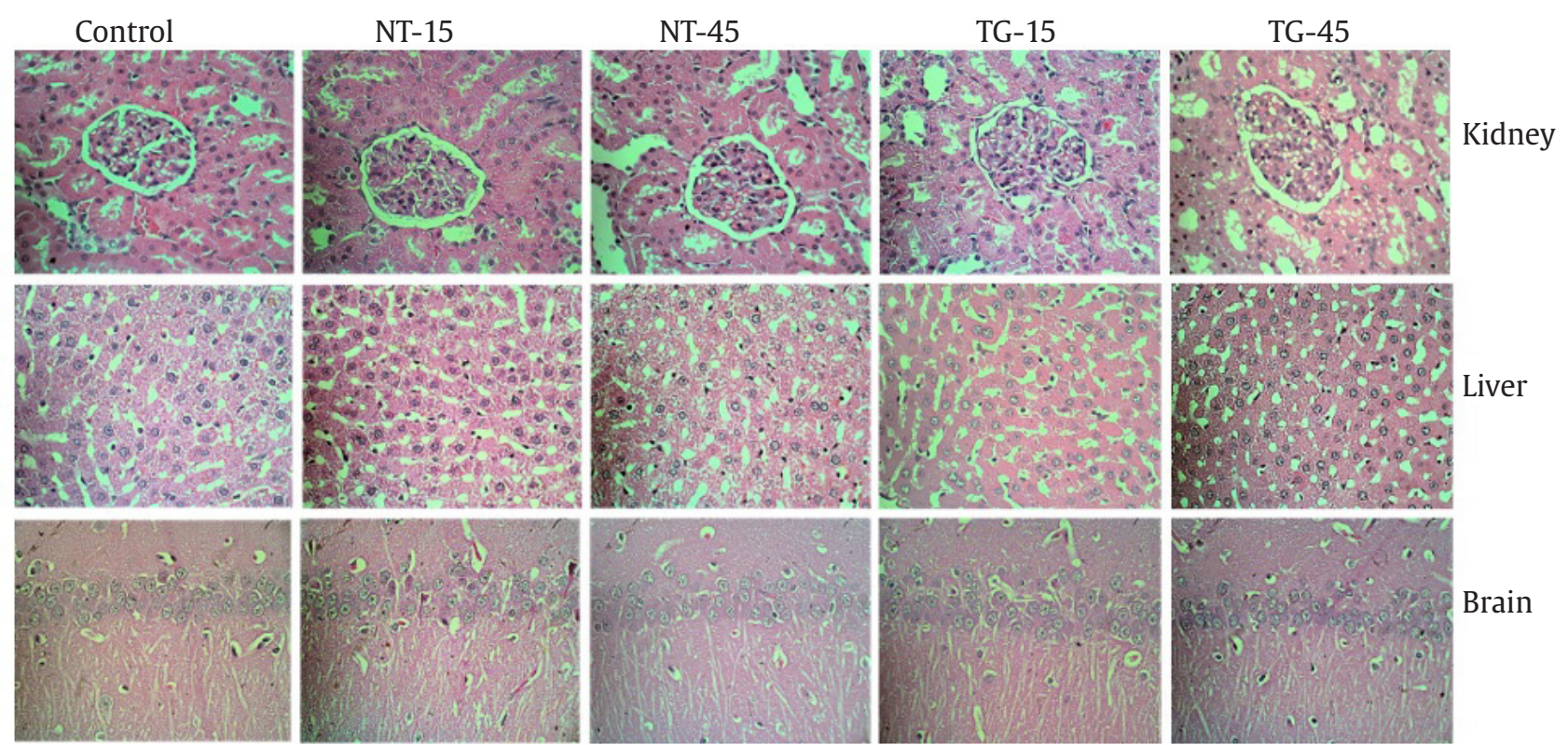

Figure 1. Histopathology of wistar rat kidney, liver, and brain stained with hematoxylin and eosin (H and $\mathrm{E})$. Rat was fed on commercial diet without common carp meal (control), commercial feed added with non-transgenic common carp meal for $150 \mathrm{~g} / \mathrm{kg}$ (NT-15) and $450 \mathrm{~g} / \mathrm{kg}$ (NT-45), and growth hormone transgenic common carp meal for 150 $\mathrm{g} / \mathrm{kg}(\mathrm{TG}-15)$ and $450 \mathrm{~g} / \mathrm{kg}(\mathrm{TG}-45)$. Magnification 400x 
Table 2. Average body weight gain of wistar rats during three weeks of treatment

\begin{tabular}{|c|c|c|c|c|c|}
\hline \multirow{2}{*}{ Treatments } & \multicolumn{4}{|c|}{ Body weight of mice (gram) } & \multirow{2}{*}{$\Delta \mathrm{W}(\mathrm{g})$} \\
\hline & Initial & Week 1 & Week 2 & Week 3 & \\
\hline Control & $139.50 \pm 19.64^{b}$ & $150.50 \pm 13.59^{a}$ & $159.33 \pm 13.17^{a}$ & $171.00 \pm 15.70^{\mathrm{a}}$ & $31.50 \pm 9.79$ \\
\hline NT-15 & $129.67 \pm 12.17^{\mathrm{ab}}$ & $197.33 \pm 29.97^{b}$ & $215.50 \pm 29.93^{b}$ & $230.00 \pm 34.94^{b}$ & $100.33 \pm 25.97^{b}$ \\
\hline NT-45 & $128.50 \pm 15.35^{\mathrm{ab}}$ & $182.50 \pm 11.27^{\mathrm{b}}$ & $200.17 \pm 12.28^{b}$ & $213.17 \pm 9.97^{b}$ & $84.67 \pm 18.10^{\mathrm{b}}$ \\
\hline TG-15 & $115.67 \pm 1.97^{a}$ & $199.33 \pm 12.06^{\mathrm{b}}$ & $207.67 \pm 10.19^{b}$ & $224.17 \pm 12.64^{\mathrm{b}}$ & $108.50 \pm 12.50^{\mathrm{b}}$ \\
\hline TG-45 & $132.50 \pm 14.07^{\mathrm{ab}}$ & $186.00 \pm 13.87^{\mathrm{b}}$ & $210.17 \pm 5.98^{b}$ & $236.33 \pm 16.21^{\mathrm{b}}$ & $103.83 \pm 20.60^{\mathrm{b}}$ \\
\hline
\end{tabular}

Control: rats fed on commercial diet without common carp fish meal supplementation; NT-15 and NT-45: rats fed on diet containing non-transgenic common carp fish meal for $150 \mathrm{~g} / \mathrm{kg}$ and $450 \mathrm{~g} / \mathrm{kg}$, respectively; TG-15 and TG-45: rats fed on diet containing transgenic common carp fish meal for $150 \mathrm{~g} / \mathrm{kg}$ and $450 \mathrm{~g} / \mathrm{kg}$, respectively. Data were presented as average value \pm SD. $\Delta \mathrm{W}$ : the subtraction of rat body weight at the end of experiment (week 3 ) and initial body weight (week 0 ). Different superscript letters within the same column showed significantly different value (Duncan test, $\mathrm{p}<0.05$ )

were not significantly different ( $\mathrm{p}>0.05$ ) with the value before treatment. The exception of this was TG-45 in SGOT and NT-45 in SGPT which were lower compared to that of before treatment was given (Table 3).

Liver function observation was based on urea and creatinine concentration measure result at initial condition (before diet treatment) and after 3 weeks diet treatment. The average urea and creatinine concentration before treatment were $42.3 \pm 2.08 \mathrm{mg} / \mathrm{dl}$ and $0.3 \pm 0.02 \mathrm{mg} / \mathrm{dl}$, respectively (Table 4 ). As presented in Table 4, urea and creatinine levels were similar before and after diet treatment ( $p>0.05)$, except urea concentration in NT-45 treatment rat, with dropped lower from before the treatment diet was given.

\section{Discussion}

Fish is believed to be the best candidate for the first marketable transgenic animal for human consumption (Zbikowska 2003). Until today, around 50 species of fish have been the subject of genetic modification (Benedict et al. 2010), and most of which are important for aquaculture, such as carps, tilapia, catfish, and salmonids. Researchers in relation with aquaculture usually runs to produce fish strains that grow faster by introducing growth hormone gene. To date, challenging condition and potential ecological risk of transgenic fish have been intensively studied (Muir and Howard 1999; Duan et al. 2010; Lian et al. 2013; Devlin et al. 2015). On the other hand, studies for food safety assessment are less rigorous. A food safety evaluation of transgenic tilapia in comparison to wild tilapia in 22 human volunteers, which is by far the only transgenic fish study performed on human (Guillen et al. 1999). No effects were detected in human healthy volunteers after the consumption of tiGH-transgenic tilapia as an alternative food source. Sun et al. (1998)
Table 3. Average of SGOT and SGPT values in rat blood fed diet containing the growth hormone transgenic common carp fish meal

\begin{tabular}{lcc}
\hline Treatments & SGOT level $($ IU $/ 1)$ & SGPT level $(I U / 1)$ \\
\hline Initial & $178.33 \pm 12.86^{\mathrm{b}}$ & $144.67 \pm 11.54^{\mathrm{b}}$ \\
Control & $110.00 \pm 30.34^{\mathrm{ab}}$ & $89.33 \pm 21.94^{\mathrm{ab}}$ \\
NT-15 & $101.00 \pm 42.32^{\mathrm{ab}}$ & $83.67 \pm 30.73^{\mathrm{ab}}$ \\
NT-45 & $123.67 \pm 31.50^{\mathrm{ab}}$ & $97.00 \pm 23.52^{\mathrm{a}}$ \\
TG-15 & $116.67 \pm 62.85^{\mathrm{ab}}$ & $95.00 \pm 51.47^{\mathrm{ab}}$ \\
TG-45 & $91.00 \pm 53.69^{\mathrm{a}}$ & $73.00 \pm 40.93^{\mathrm{ab}}$ \\
\hline
\end{tabular}

Control: rats fed on commercial diet without common carp fish meal supplementation; NT-15 and NT-45: rats fed on diet containing non-transgenic common carp fish meal for $150 \mathrm{~g} / \mathrm{kg}$ and $450 \mathrm{~g} / \mathrm{kg}$, respectively; TG-15 and TG-45: rats fed on diet containing transgenic common carp fish meal for $150 \mathrm{~g} / \mathrm{kg}$ and $450 \mathrm{~g} / \mathrm{kg}$, respectively. Data were presented as average value \pm SD. Different superscript letters within the same column showed significantly different value (Duncan test, $\mathrm{p}<0.05$ )

Table 4. Average serum urea and creatinine concentration in rat fed diet containing growth hormone transgenic common carp meal

\begin{tabular}{lcc}
\hline Treatments & Urea level $(\mathrm{mg} / \mathrm{dl})$ & Creatinine level $(\mathrm{mg} / \mathrm{dl})$ \\
\hline Initial & $42.33 \pm 2.08^{\mathrm{b}}$ & $0.3 \pm 0.02^{\mathrm{a}}$ \\
Control & $27.33 \pm 6.81^{\mathrm{ab}}$ & $0.2 \pm 0.05^{\mathrm{a}}$ \\
NT-15 & $30.33 \pm 8.14^{\mathrm{ab}}$ & $0.2 \pm 0.08^{\mathrm{a}}$ \\
NT-45 & $29.67 \pm 11.06^{\mathrm{a}}$ & $0.3 \pm 0.10^{\mathrm{a}}$ \\
TG-15 & $27.67 \pm 11.68^{\mathrm{ab}}$ & $0.2 \pm 0.09^{\mathrm{a}}$ \\
TG-45 & $23.33 \pm 13.01^{\mathrm{ab}}$ & $0.2 \pm 0.09^{\mathrm{a}}$
\end{tabular}

Control: rats fed on commercial diet without common carp fish meal supplementation; NT-15 and NT-45: rats fed on diet containing non-transgenic common carp fish meal for $150 \mathrm{~g} / \mathrm{kg}$ and $450 \mathrm{~g} / \mathrm{kg}$, respectively; TG-15 and TG-45: rats fed on diet containing transgenic common carp fish meal for $150 \mathrm{~g} / \mathrm{kg}$ and $450 \mathrm{~g} / \mathrm{kg}$, respectively. Data were presented as average value \pm SD. Different superscript letters within the same column showed significantly different value (Duncan test, $\mathrm{p}<0.05$ ) 
fed cats with GH transgenic carp for three months and it concluded that there is no difference in the physiological indicator and hematological index in cats fed with GH transgenic carp.

In our previous research, we fed GH transgenic common carp fresh meat to catfish and giant freshwater prawn which acted as model fish to evaluate the effect of feeding TG common carp to carnivorous fish (Alimuddin et al. 2013). The result of that research showed that there was no effect on survival rate, feeding response, and growth of both catfish and giant freshwater prawn. This study was conducted to test for possible adverse effects of using $\mathrm{GH}$ transgenic common carp for food with the purpose of providing more data of food safety test before its marketing. Within three weeks of observation, the research result showed that there was no change in behavior, rat-rat interaction within one cage, and response towards given diet and water. Histological examination of kidney, liver, and brain of the rats also did not show any changes (Figure 1). Differences only appeared in body weight between rats given diet containing TG$\mathrm{Ccm}$ and rats given no $\mathrm{Ccm}$ (control), while the body weight between NT- and TG-Ccm treatment rats were similar-hovering around 84.67-108.50g (Table 2). This weight shows around 2.7-3.4 fold higher compared to rats fed without $\mathrm{Ccm}$ supplementation. However, the weight is still within normal range. Normal Wistar rat body weight with 3-4 months of age is 195-269 gram (ARC 2015).

Furthermore, the addition of $15 \%$ and $45 \%$ common carp meal in this study showed no difference in body weight increase between rats fed on TG-Ccm and NT$\mathrm{Ccm}$. This showed that within the condition of this research, the growth of test rat was not affected by the difference of amino acid and lipid acid contents in transgenic and non-transgenic common carp (Alimuddin et al. 2014). The higher growth rate of rats given $\mathrm{Ccm}$ supplemented diet compared to those not fed $\mathrm{Ccm}$ revealed the effect of common carp meal nutrient.

Based on SGOT and SGPT values, the liver function of treatment rat did not suffer anomalies from feeding since both SGOT and SGPT values were in normal range. The normal range for SGOT and SGPT values for male Wistar rat aged 2 and 4 months are 74-143 IU/l and 63-175 IU/l, respectively (Giknis and Clifford 2008). Urea and creatinine level showed that rat kidney function had no anomalies from feeding with both urea and creatinine level within the normal range (Table 4). The normal range of urea level for male Wistar rat aged 3 months is $15.0-44.5 \mathrm{mg} / \mathrm{dl}$, while creatinine level normal range is $0.2-0.6 \mathrm{mg} / \mathrm{dl}$ (Giknis and Clifford 2008). Wistar rat fed on the commercial diet supplemented by growth hormone transgenic common carp meal as much as $150 \mathrm{~g} / \mathrm{kg}$ and $450 \mathrm{~g} /$ $\mathrm{kg}$ did not show changes in organ histology, behavior, and physiology. Therefore, the ingredient is considered non-toxic.

\section{Acknowledgements}

This research was partially supported by PSU Research Grant No: 53/IT3.11/LT/2014 from Ministry of Research and Higher Education, Indonesia. The authors would like to thank Rangga SPi. and Lina Mulyani for their help in preparing the test feed, and the staff of Faculty of Veterinary Medicine, IPB for their help in rat rearing.

\section{References}

Alimuddin et al. 2011. Identification of Majalaya common carp strain resistant to KHV infection using Cyca$\mathrm{DAB} 1{ }^{*} 05$ allele as the marker. Indonesian Aquaculture Journal 6:157-163.

Alimuddin et al. 2012. Fast growth and koi herpes virusresistant common carp strain: production of second generation. In: Seminar Proceeding of IPB Research ISBN 978-602-8853-16-3. pp. 16-28.

Alimuddin et al. 2013. Histamine and testosterone levels, physiological and histological response of carnivorous fish fed on transgenic fish flesh. In: Seminar Proceeding of IPB Research. ISBN 978-602-8853-19-4. 978-6028853-20-0. pp. 1-10.

Alimuddin et al. 2014. Cultured performance and nutrient content of growth hormone transgenic common carp. In: Seminar Proceeding of IPB Research. ISBN 978-6028853-22-4. 978-602-8853-23-1. pp. 1-10.

Armario A. 2006. The hypothalamic-pituitary-adrenal axis: what can it tell us about stressors. CNS and Neurol Disord Drug Targets 5:485-501.

[ARC] The Animal Resources Centre. 2015. http://www.arc. wa.gov.au/.

Benedict Met al. 2010. Defining Environmental Risk Assessment Criteria for Genetically Modified Fishes to be placed on the EU Market (Scientific/Technical Report submitted to EFSA). Parma: European Food Safety Authority (EFSA). pp. 200.

Devlin RH et al. 1994. Extraordinary salmon growth. Nature 371:209-210.

Devlin RH et al. 2015. Assessing ecological and evolutionary consequences of growth-accelerated genetically engineered fishes. BioScience 65:685-700.

Duan $\mathrm{M}$ et al. 2010. Increased mortality of growthenhanced transgenic common carp Cyprinus carpio L. under short-term predation risk. Journal of Applied Ichthyology 26:908-912.

[FDA] Food and Drug Administration. 2016. http: / / www.fda.gov / AnimalVeterinary / DevelopmentApprovalProcess/GeneticEngineering/ GeneticallyEngineeredAnimals/ucm280853.htm).

Galef BGJ. 2005. Social Learning. In: The Behavior of the laboratory rat: a Handbook with Tests. Whishaw IQ and Koib B (Eds.). pp. 363-370.

Geiger BM et al. 2009. Deficits of mesolimbic dopamine neurotransmission in rat dietary obesity. Neuroscience 159:1193-1199. 
Giknis MLA, Clifford CB. 2008. Clincal Laboratory Parameter for Crl:WI(Han). Charles River Laboratories. pp. 14. [www.criver.com/files/pdfs/rms/wistarhan/rm_ rm_r_wistar_han_clin_lab_parameters_08.aspx.

Guillén I et al. 1999. Safety evaluation of transgenic tilapia with accelerated growth. Mar Biotechnol 1:2-14.

Kiernan JA. 1990. Histological and Histochemical Methods: Theory and Practice. $2^{\text {nd }}$ edition. England: Pergamon Press pp. 10-31.

Kobayashi SI et al. 2007. Transgenic Nile tilapia Oreochromis niloticus over-expressing growth hormone show reduced ammonia excretion. Aquaculture 270:427435.

Kurdiantho et al. 2016. Growth, survival and body composition of transgenic common carp Cyprinus carpio third generation expressing tilapia growth hormone cDNA. HAYATI J Biosci 23:150-154.

Lian $\mathrm{H}$ et al. 2013. Transgenic common carp do not have the ability to expand populations. Plos One 8:1-6.
Muir WM, Howard RD. 1999. Possible ecological risks of transgenic organism release when transgenes affect mating success: sexual selection and the Trojan gene hypothesis. Proc Natl Acad Sci 96:13853-13856.

Stratford TR, Kelle AE. 1997. GABA in the nucleus accumbens shell participates in the central regulation of feeding behavior. The Journal of Neuroscience 17:4434-4440.

Sun XW et al. 1998. Research on transgenic fish as food. Chin High Technol Lett 3:45-49.

[VAPHS] VA Pittsburgh Healthcare System. 2016. Animal Research Facility: Standard Operating Procedures. http://www.pittsburgh.va.gov/Research/docs/ animal-research-facility-standard-operatingprocedures.pdf

Zbikowska HM. 2003. Fish can be first-advances in fish transgenesis for commercial applications. Transgenic Research 12:379-389. 